Int. J. Dev. Biol. 48: 707-717 (2004)

doi: $10.1387 / \mathrm{ijdb} .041900 \mathrm{wg}$

\title{
Historical perspective on the development and evolution of eyes and photoreceptors
}

\author{
WALTER J. GEHRING* \\ Dept. Cell Biology, Biozentrum, University of Basel, Switzerland
}

\begin{abstract}
The development and evolution of eyes is an "old problem" in biology, which required a special treatment in Charles Darwin's "Origin of the species" (1882) under the heading of "Difficulties of the theory". Darwin postulated a simple and imperfect eye, as a prototype, which can vary and evolve under natural selection into more complex and perfect eyes. Based upon morphological criteria and the different modes of development of the different kinds of eyes, neodarwinists have postulated that the various eye-types are polyphyletic in origin and that the eyes have evolved independently in the various animal phyla. Recent developmental genetic experiments and molecular phylogenetic analyses cast serious doubts on this interpretation and argue strongly for a monophyletic origin of the eyes from a Darwinian prototype and subsequent divergent, parallel and convergent evolution leading to the various eye-types.
\end{abstract}

KEY WORDS: prototype, phylogeny, divergence, convergent evolution

\section{The different modes of eye development}

The development of the eye has become an important research topic of experimental embryology and evolutionary biology as early as 1901 when Hans Spemann began to study eye development in the amphibian embryo. In vertebrates the eye develops from the neural plate as an evagination from the brain, forming the so-called optic vesicle, which subsequently invaginates to form the optic cup. The inner layer of the optic cup forms the retina with its photoreceptor cells, whereas the outer layer gives rise to the pigment epithelium which absorbs the light in the back of the retina. By contrast the lens and the cornea arise from the skin ectoderm. As shown in one of the earliest experiments of Spemann (Fig. 1A), removal of the eye vesicle of the frog embryo leads to the absence not only of the eye on the operated side, but also of the lens. Apparently, a stimulus from the optic vesicle was required for lens formation. However, this experiment did not answer the question of whether the optic vesicle merely served to trigger lens formation, or whether it played an instructive role. To answer this question Spemann suggested two experiments: to transplant the optic vesicle to an ectopic site, under the flank epidermis, in order to bring it into contact with foreign epidermis (Fig. 1B), or alternatively, to replace the head epidermis over the optic vesicle with flank epidermis. The American embryologist Warren Lewis had independently conceived the same idea and performed these reziprocal transplantation experiments on the American frog Rana palustris (Lewis, 1904 and 1907). In both experiments typical lenses were formed in the flank epidermis, which suggested an instructive role of the optic cup. Lewis and Spemann deserve credit for the first experimental demonstration of a case of embryonic induction, even though they did not use the term induction at that time. However, it soon turned out that there were large differences among different species of amphibians, and Spemann obtained a different result with the European frog Rana esculenta (Spemann, 1936). In this species, the removal of the eye anlage from the neural plate i.e. even at an earlier stage, did not prevent the formation of well differentiated lenses. Later these induction experiments led to the discovery of the organizer, which Spemann interpreted in terms of interactions between different embryonic tissues; but the possibility that genes might regulate developmental processes was hardly considered (see Hamburger, 1988). Even after Schotté, a collaborator of Spemann, had demonstrated the influence of the genome in a classical experiment; Spemann was not convinced of the importance of the genes in development. Schotté had transplanted ventral skin ectoderm from a frog gastrula into the mouth region of a newt gastrula. The transplanted frog tissue formed mouth structures in the newt larva, but the cells differentiated into a frog mouth with horny jaws and suckers, rather than the typical newt structures, dentin teeth and balancers. This experiment clearly indicated that the capacities of the transplanted tissue for differentiation is determined by the genome, but Spemann like most other embryologists with the

\footnotetext{
*Address correspondence to: Dr. Walter Gehring. Dept. Cell Biology, Biozentrum, University of Basel, Klingelbergstrasse 70, 4056 Basel, Switzerland, 51. Fax: +41-61-267-2078. e-mail: walter.gehring@unibas.ch

\# This article is dedicated to the memory of Claude Hélène.
} 
exception of Thomas $\mathrm{H}$. Morgan, failed to recognize the importance of the genes (Hamburger, 1988).

In contrast to the camera-type eye of vertebrates the compound eyes of insects have a very different structure. They consist of hundreds or thousands of individual eye facets each with its own lens and its own set of photoreceptor cells. The insect eye is not only structurally different, but it also has a completely different mode of development. In Drosophila, for example, the eye primordia form as an invagination of the embryonic ectoderm which gives rise to the eye imaginal disc of the larva. During metamorphosis the eye disc organizes itself to form the compound eye whose photoreceptor cells extend their axons backwards from the periphery to establish contact with the brain. As first shown by Beadle and Ephrussi (1936) an eye disc of a donor larva can be transplanted into the body cavity of a host larva where it metamorphoses with its host and differentiates autonomously into an adult eye. The completely different structure and mode of development has led to the dogma that the eyes of vertebrates and insects are non-homologous structures and have originated independently in the two different phyla.

The camera-type eye of cephalopods is structurally very similar to the vertebrate eye, with one major difference which is the orientation of the photoreceptor cells. In contrast to the vertebrate eye which develops as an evagination of the brain, the cephalopod eye forms as an invagination of the ectoderm, so that the differentiated photoreceptor cells are oriented towards the light source. In contrast, the photoreceptor cells of vertebrates are facing in the opposite direction. The different mode of development has been taken as evidence for an independent evolutionary origin of the cephalopod eye, and for a convergent evolution.

Based upon morphological and embryological considerations Salvini-Plawen and Mayr (1961) claimed that photoreceptors have

\section{A}

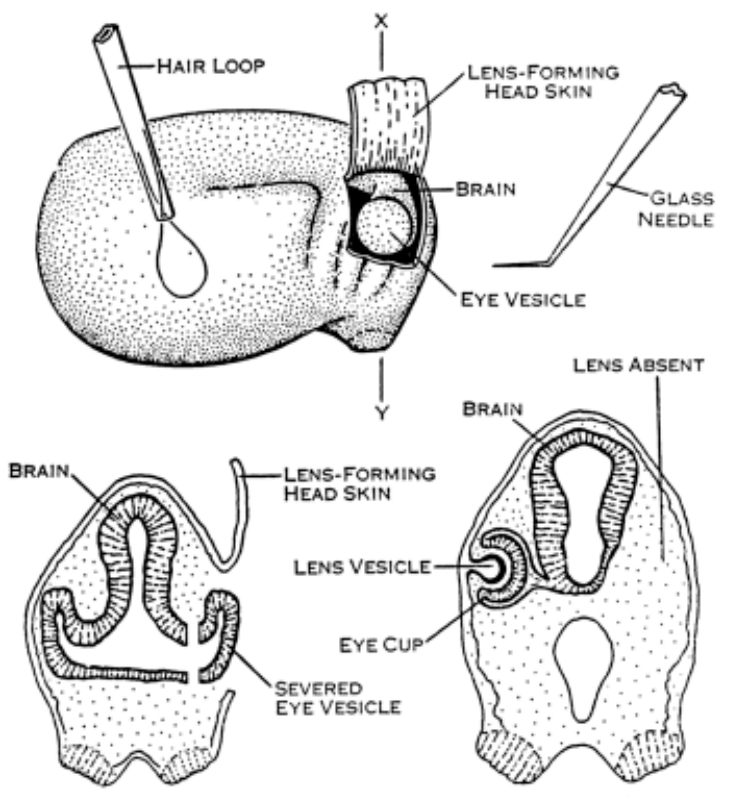

originated independently in at least 40 but possibly up to 65 or more phyletic lines and they strongly adhere to the dogma "that the lens eye of a vertebrate and the compound eye of an insect are independent evolutionary developments". Even on purely morphological grounds it seems very unlikely that the various eyes originated $40-65$ times independently in evolution, since in the phylum of molluscs, for example, and even within a single class of molluscs, the Bivalves (clams, oysters and mussels), all of the major different eye types can be found: The cockle (Cardium) has a camera-type eye, the ark shell ( $A$ rca) has a compound eye and the scallop (Pecten) has mirror eye. It seems highly unlikely that these originated independently, but rather that they arose by divergent evolution from a common ancestor.

\section{The genetic control of eye development}

The importance of the genes controlling development was largely neglected by the classical embryologists. However, T.H. Morgan (1934) was aware of the importance of genetics for understanding embryology and he first advanced the idea that development is controlled by differential gene activity. Through the studies of E. Hadorn and others it became clear that genes are essential for normal development to occur, and that mutations in essential genes lead to the disruption of development and to lethality (Hadorn, 1961). It is important to notice that the field of embryology evolved into developmental biology by the fusion with three different branches of biology. This is clearly reflected by the fact the journal of "Developmental Biology" was launched by three founding fathers Jean Brachet, a biochemist (molecular biologist), Ernst Hadorn, a geneticist, and Paul Weiss, a cell biologist, who shared a common interest in development. In more recent years we have witnessed the fusion of developmental biology with

B

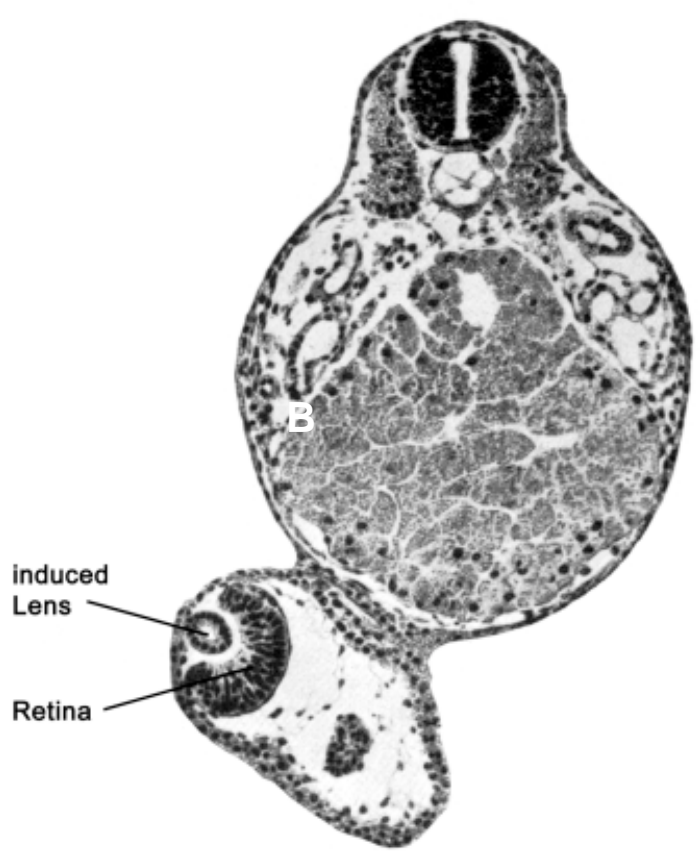

Fig. 1. (A) Exstirpation of the eye vesicle in an amphibian embryo leading to the absence of both the eye cup and the lens (after Hamburger, 1988). (B) Section across a Triturus taeniatus larva with a transplanted eye cup, which has induced an ectopic lens in the flank of the larva (after Spemann, 1936). 
Fig. 2. (A) Induction of ectopic eyes by targeted expression of the eyeless gene on the antenna and wing of Drosophila. (B) Induction of ectopic eyes on the legs of Drosophila by targeted expression of the twin of eyeless gene.
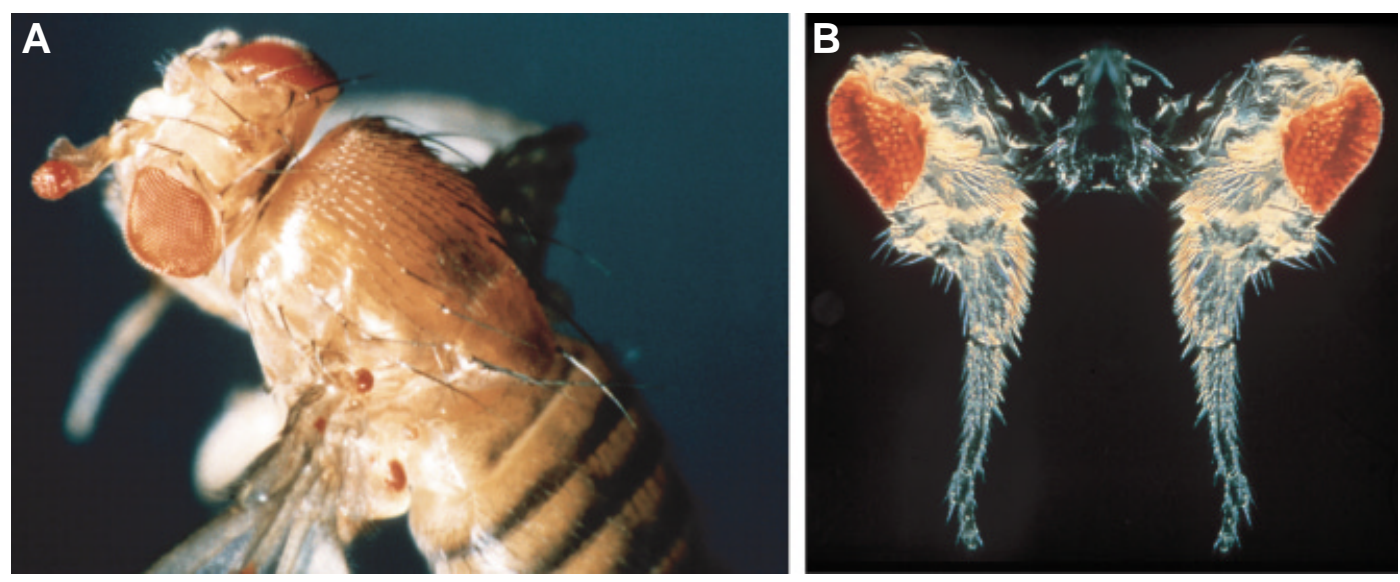

yet another field, with evolutionary biology, which has been equally fruitful.

As early as 1915 Hoge isolated the first Drosophila mutation disrupting eye development, which she called eyeless (ey). It shows a rather variable phenotype from more or less reduced eyes to a complete loss of compound eyes on one or both sides of the head. A similar mutation Smalleye (Sey) was found in mice. Homozygous Sey embryos are eyeless, noseless, lack large parts of the forebrain and die as foetuses, whereas heterozygotes develop to adult mice with small eyes, suggesting that the eye is critically affected. A similar mutant syndrome Aniridia has been described in humans. Heterozygous human Aniridia patients have an iris which is reduced to various degrees, and two homozygous mutant foetuses have been described which were eyeless and noseless, suffered brain damage and died prior to birth. Using the Drosophila paired box as a probe Walther and Gruss (1991) cloned the Pax 6 gene of the mouse, which was shown to be affected by the Sey mutation (Hill et al., 1991). Similarly the human Aniridia gene was cloned and shown to encode human Pax 6 (Ton et al., 1991). Pax 6 encodes a transcription factor with two DNA binding domains, a paired domain and a homeodomain, but it lacks the octapeptide found in some other members of the Pax gene family. By pure serendipity my graduate student Rebecca Quiring cloned the Drosophila homolog of Pax 6 and Uwe Walldorf subsequently showed that it corresponds to the gene affected by the eyeless mutation discovered eighty years before by Hoge. Therefore, mutations in same Pax 6 gene disrupt eye development in both mammals and insects.

Subsequently we discovered that in higher insects Pax 6 has undergone a gene duplication (Czerny et al., 1999). Whereas apterygote (springtails) and hemimetabolous insects (grasshoppers) have a single Pax 6 homolog, holometabolous insects (Drosophila and silk worms) have two genes. The Drosophila paralog was designated as twin of eyeless (toy). We have isolated deletions and null alleles for both eyand toy (Kurusu et al., 2000; Kammermeier et al., 2001; Flister et al., in preparation) and found that the two genes have diverged with respect to their function; ey loss-of-function mutants mainly affect the compound eyes, which are partially or completely missing, and leave the head with the ocelli intact; whereas toy mutants are almost headless, lacking the head capsule with the ocelli and the antennae, but retaining the proboscis. In fact, a toy mutation had already been found by
Hochman et al., (1964) as a lethal mutation on the fourth chromosome, but only recently it has been identified as a toy mutation which shows a headless phenotype (Kronhamn et al., 2002). Dissection of the headless toy pupae, however, reveals that two "balls" of compound eye structures are found in the thorax. This indicates ey and toy have functionally diverged, but they are still capable of partial complementation; $\mathrm{ey}^{+}$is able to partially rescue the compound eyes in toy; whereas toy ${ }^{+}$rescues the ocelli, headcapsule and antennae in ey- (Punzo et al., 2002; Kronhamn et al., 2002; Flister et al., in preparation).

\section{Pax 6 is a master control gene for eye development}

The observation that mutations in Pax 6 disrupt eye development in both mammals and insects suggested to me that Pax 6 might be a master control gene for eye development in both vertebrates and invertebrates. Since there are a number of genes disrupting eye development at various levels of the genetic hierarchy, the loss-of-function mutations alone do not allow the identification of master control genes which are on the top of the genetic hierarchy. Therefore, we attempted to induce ectopic eyes in gain-of-function mutations of both Drosophila eyeless and mouse Pax 6. Using the gal 4 system (Brand and Perrimon, 1993) for targeted expression of $e y$, we succeeded in inducing complete compound eyes (Fig. 2A) on the antennae, wings and legs of the fly (Halder et al., 1995). The ectopic expression of a single gene, ey, is inducing all the subordinate genes required for the induction of an eye morphogenetic field in the respective imaginal discs, which subsequently differentiates into ectopic compound eyes. The Pax 6 paralog twin of eyeless (toy) is also capable of inducing eye morphogenesis (Fig. 2B). The ectopic eyes appear to be normal in morphology and a fraction of the ectopic eyes formed on the antenna also shows a normal electroretinogram which indicates that they are functional eyes (P. Callaerts et al., unpublished).

In order to test whether the Pax 6 homologs of insects and mammals serve homologous functions we expressed the mouse Pax 6 gene ectopically in Drosophila (Halder et al., 1995). As shown in Fig. $3 \mathrm{~A}, \mathrm{~B}$ the mouse Pax 6 gene is capable of inducing ectopic compound eyes in Drosophila. In a reciprocal experiment we have shown that the Drosophila eyeless and twin of eyeless genes are also functional in Xenopus (vertebrate) embryos (Onuma etal., 2002) and can induce retina, retinal pigment epithelium, and lens structures (Fig. $3 \mathrm{C}-\mathrm{H}$ ). 
Fig. 3. $(A, B)$ Scanning electron-micrograph of an ectopic eye on the antenna induced by the ectopic expression of the mousesmall eye gene (= Pax 6). (A) Overview. (B) Higher magnification. (C-H) Induction of ectopic eye structures by injection of 2-cell stage xenopus embryos with Drosophila eyeless andtwin of eyeless mRNA. (C) Uninjected control side. (D,E,F) Induction of extrapigment epithelium with eyeless RNA. (G) Eye duplication induced by injection of 2 ng of twin of eyeless RNA. (H) Induction of additional retina structures by injecting twin of eyeless RNA (after Onuma et al.).
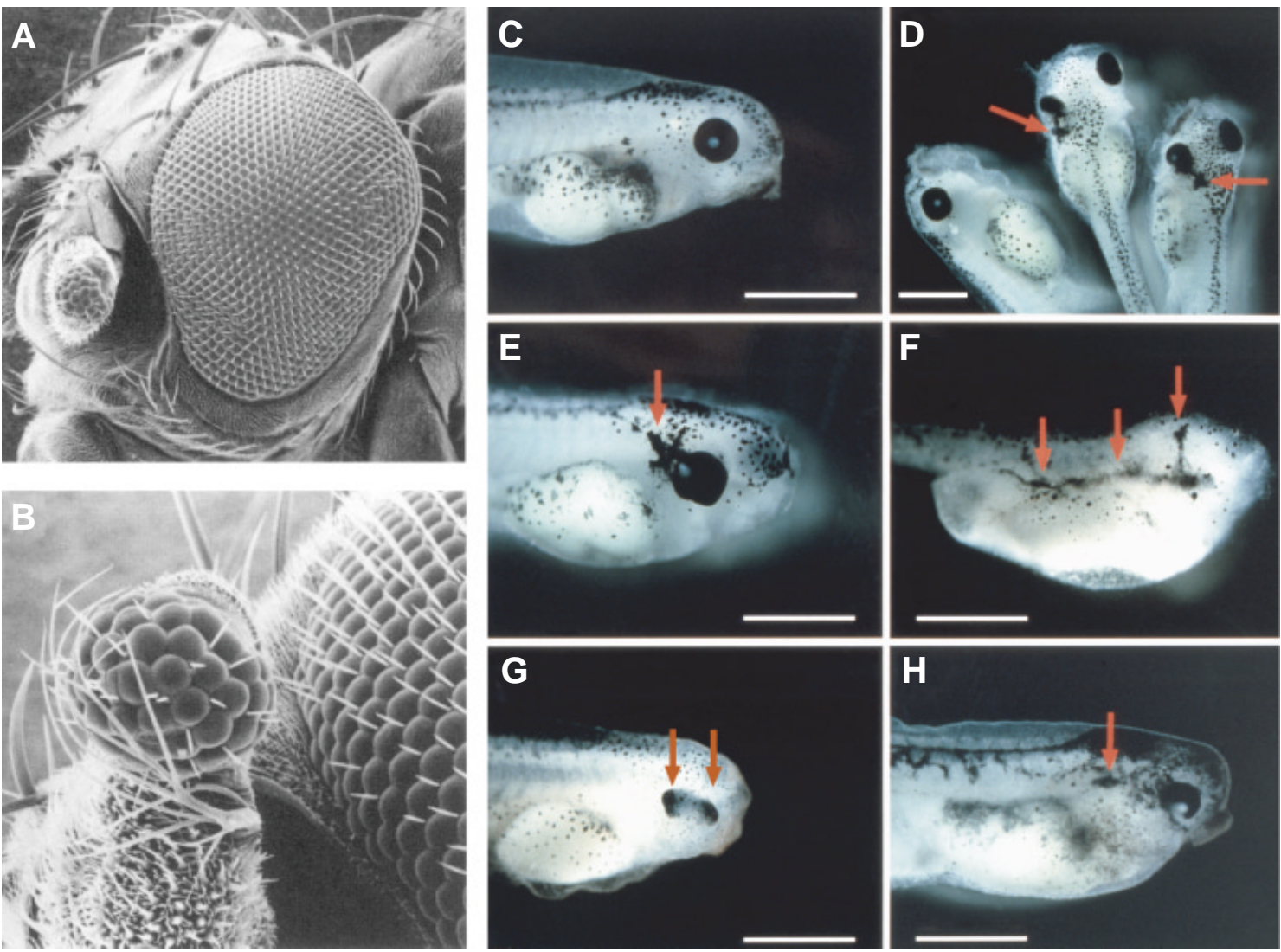

\section{The genetic program for eye development}

The experiments described above clearly indicate that Pax 6, which is on the top of the genetic hierarchy, is shared by mammals and insects, which poses the question of how much of the genetic cascade leading to eye morphogenesis is conserved and how many new genes have to be recruited into the eye morphogenetic pathway to make the difference between an insect compound eye and a mammalian camera-type eye. We have approached this question first by identifying the immediate target genes of $e y$ by functional genetics. The sine oculis (so) homeobox gene was shown to be a direct target of both eyand toy (Punzo et al., 2002). By combining results from various laboratories we propose a scheme as shown in Fig. 4, which indicates that toyand eyare on the top of the hierarchy and that there are several feedback loops to ensure normal eye development.

Using whole genome microarrays we have begun to unravel the entire eye morphogenetic pathway starting with the establishment of an eye morphogenetic field in the imaginal leg disc in which an eye has been induced, and comparing the pattern of expressed genes to that of normal eye and leg discs (Michaut et al., 2003). At this early stage of eye development we mostly find transcription factors to be expressed, indicating that we are on the top of the genetic hierarchy. We are extending these studies to the later developmental stages and we plan to compare the transcriptome of Drosophila with that of the mouse. Besides the highly conserved transcription factor genes, there are also important differences between mammals and insects; for example, the homeobox gene $R x$ is essential for vertebrate eye development
(Mathers et al., 1997) and is expressed in rod and cone ciliary photoreceptors, whereas in Drosophilait is expressed in the brain only, but not in the rhabdomeric photoreceptors of the eye (Eggert et al., 1998; Davis et al., 2003).

\section{New perspectives in eye evolution}

Charles Darwin in "The Origin of Species" had great difficulties with eye evolution and devoted an entire chapter to "Difficulties of the Theory" in which he discusses "Organs of extreme Perfection and Complication".

"To suppose that the eye with all its inimitable contrivances for adjusting the focus to different distances, for admitting different amounts of light and for the correction of spherical and chromatic aberration, could have been formed by natural selection, seems, I freely confess, absurd in the highest degree". But then he continues: "Reason tells me, that if numerous gradations from a simple and imperfect eye to one complex and perfect can be shown to exist, each grade being useful to its possessor, as is certainly the case; if further, the eye ever varies and the variations be inherited, as is likewise certainly the case; and if such variations should be useful to any animal under changing conditions of life, then the difficulty of believing that a perfect and complex eye could be formed by natural selection, though insuperable by our imagination, should not be considered as subversive of the theory". This pushes the question of eye evolution back to the problem of how the first primitive eye, the prototype has evolved. The evolution of an eye prototype would seem to be a highly improbable stochastic event, since selection can only work after 
the various components are assembled into a prototype that is at least partially functional as a photoreceptor organ. "The simplest organ which can be called an eye consists of an optic nerve, surrounded by pigment-cells and covered by trans/ucent skin, but without any lens or other refractive body". Such primitive eyes are found, for example, in certain flatworms and allow directional vision. Hesse (1897) has described the eyes of Planaria torva which consist of three photoreceptor cells and a single pigment cell only, and there is a planarian species in Japan (Polycelis auricularia) which has multiple eyes with one photoreceptor cell and one pigment cell only, which corresponds exactly to the Darwinian prototype (Kiyokazu Agata, pers. comm.). A two-celled prototypic eye is also found in Platynereis larvae (Polychaeta) consisting of a single rhabdomeric photoreceptor cell and a pigment cell, which subsequently develops into a pigment cup eye (Arendt etal., 2002). For the present discussion we adopt Darwin's definition of an eye as an organ consisting of at least two different cell-types, photoreceptor cells and pigment cells. The "eyes" of protists are organelles (and not organs) formed within a single cell and arise by the assembly of molecules within a cell rather than by the assembly of different cells, which is a fundamental difference with respect to the genetic control of morphogenesis. Land and Nilsson (2002) adopt another definition of an eye and restrict the term eye to organs of spatial vision, but they do not distinguish the more primitive multicellular photoreceptor organs from eye organelles which are formed with single cells. Since the evolution of a prototypic eye is a highly improbable stochastic event that is not driven by selection, the hypothesis of a polyphyletic origin of the eyes, arising 40 to 65 times independently, is extremely unlikely and incompatible with Darwin's ideas.

It has been known for some time that all metazoa share the same photoreceptor pigment rhodopsin (Goldsmith, 1990; Spudich et al., 2000). Rhodopsin is a molecule of ultimate sensitivity since it allows the detection of a single quantum of light, and by amplification of this signal it can trigger a nerve impulse. Sharing of the same photoreceptor pigment by all metazoa is compatible with a monophyletic origin of the eyes, but it does not provide strong support for this hypothesis, since rhodopsin is subject to strong functional evolutionary constraints. The only function of rhodopsin is light perception. By contrast, the conservation of $P a x$ 6 as a master control gene for eye development is not functionally constrained. Pax 6 is a transcription factor which basically can control any target gene endowed with the appropriate gene regulatory (enhancer or silencer) sequences. There is no functional necessity for Pax 6 to be consistently involved in eye development. Therefore, if Pax 6 is always involved in eye development, this must be for evolutionary (historical) reasons. The same argument has been made for the genetic code. There is no functional necessity for AAA to encode lysine, or TAA to be a stop codon. The fact that a few exceptional codons have been found in mitochondria and protozoa demonstrates that there is no functional constraint for a certain codon usage. Therefore, the finding that the genetic code is conserved from $\mathrm{E}$. coli to humans indicates that all the known organisms on earth go back to a common ancestor. Similarly the finding that insects and mammals share the same master control gene for eye development indicates that Pax 6 was present in the last common ancestor of mammals and insects. Pax 6 has now been identified in most animal phyla ranging from flat worms (planarians) and ribbonworms (nemerteans) to amphioxus and vertebrates (Gehring and Ikeo, 1999) indicating that Pax 6 is universal at least among Bilateria. This leads to the proposal that the bilaterian eye is monophyletic in origin (Gehring and lkeo, 1999). A possible scenario for eye evolution is outlined in Fig. 5.

This interpretation has been challenged by Gerhart and Kirschner (1997) and by Land and Nilson (2002) who claim that ciliary and rhabdomeric photoreceptors have evolved independently and that vertebrates and invertebrates use fundamentally different signalling pathways in photoreception. However, as shown by Arendt and Wittbrodt (2001) and Arendt (2003) ciliary and rhabdomeric photoreceptor cells co-exist in many bilaterian groups and even within the same species as e.g. Pecten (Nilson, 1994) indicating clearly that they did not evolve from independent origins. Furthermore, the analysis of the effector genes of rhabdomeric and ciliary photoreceptor cells shows that both rhabdomeric opsins and cililary opsins are found in both vertebrates and invertebrates (Arendt, 2003), which is in line with the assumption of a single pre-bilaterian photoreceptor cell precursor which diverged into rhabdomeric and ciliary cell types already present in Urbilateria. After their splitting apart the two sister cell types specialized on different signal transduction pathways, phosphodiesterase in the ciliary receptor-type and phospholipase $C$ in the rhabdomeric photoreceptors (Arendt, 2003). This molecular comparative analysis supports a monophyletic origin of the bilaterian eye. It should also be pointed out the camera-type eyes can be formed either by ciliary photoreceptor cells (vertebrates) or rhabdomeric photoreceptors (cephalopods), and compound eyes can be formed either by rhabdomeric photoreceptors (insects) or by ciliary photoreceptors (ark clams). In his latest book Ernst Mayer (2001) agrees that the old dogma of 40 times independent evolution may no longer hold.

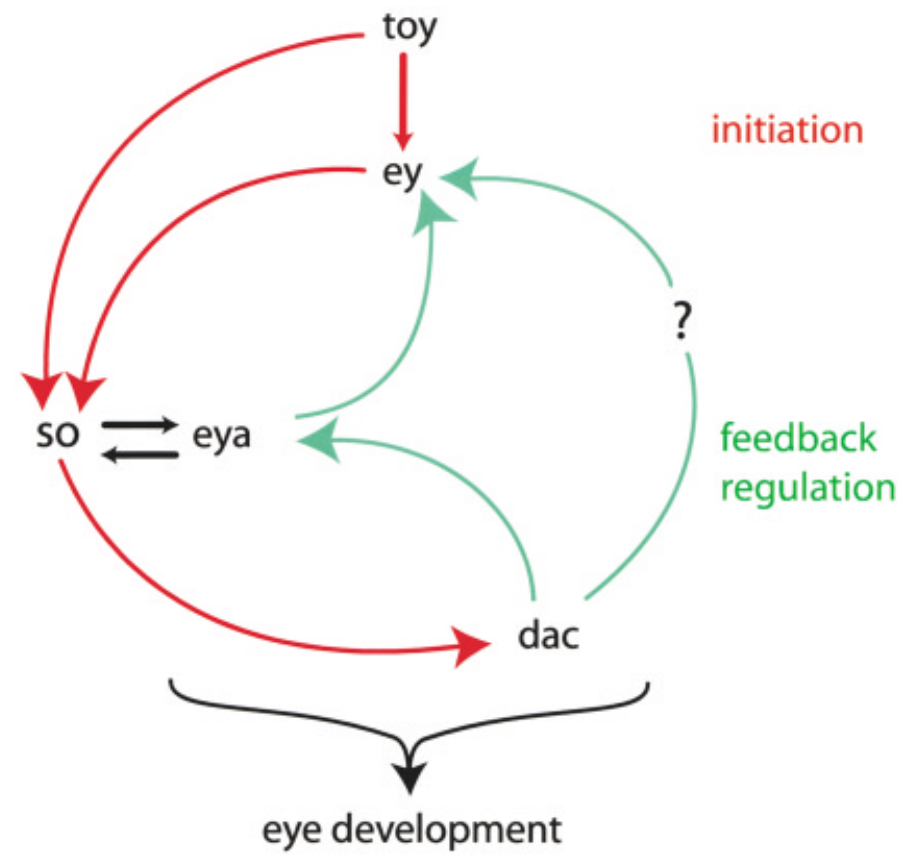

Fig. 4: Gene regulatory network controlling eye determination in Drosophila. 
The mere presence of a Pax 6 gene in a given organism and its expression in the eyes is only a correlation and for some of the more exotic animals it is difficult to obtain functional genetic evidence for the involvement of Pax 6 in eye evolution. However, RNA interference and gene transfer experiments provide functional genetic evidence that $P a x 6$ and sine oculis are involved in eye development in planarians. In order to study the universality of Pax 6 control in eye development we have adopted a novel strategy; if Pax 6 expression is conserved in evolution, the gene regulatory sequences (enhancers and silencers) of its target genes also have to be conserved. E. Wimmer has analyzed a Pax 6 specific enhancer (P3) which is found e.g. in front of the rhodopsin genes ranging from fruit flies to humans (Berghammer et al., 1999). By fusing three copies of this gene regulatory element to a minimal promoter and Green Fluorescent Protein (GFP) Horn and Wimmer (2000) have constructed transposon-derived vectors which function in a wide variety of organisms. Transgenic animals carrying these vectors generally express GFP in their eyes. By electroporation we have produced transgenic planarian lines expressing the P3-GFP marker in the photoreceptor cells in the eyes (Fig. 6; González-Estévez et al., 2003). This confirms Pax 6 activity in the eyes of flat worms and indicates that the same gene regulatory elements are used as in other metazoa. However, not only Pax 6 function is conserved in planarians, but also sine oculis, the next downstream target gene of Pax 6 in Drosophila, is also functionally conserved; RNA interference experiments demonstrate that the sine oculis homolog in planarians is required for eye regeneration as well (Pineda et al., 2000).

Cnidarians are generally considered to be ancestral to Bilaterians. They

Fig. 5. Hypothetical evolution of photosensitive cells containing rhodopsin as a light receptor and monophyletic evolution of the various eye-types starting from a Darwinian prototype eye consisting of a single photoreceptor cell and a pigment cell assembled under the control of Pax 6 (after Gehring and Ikeo, 1999).

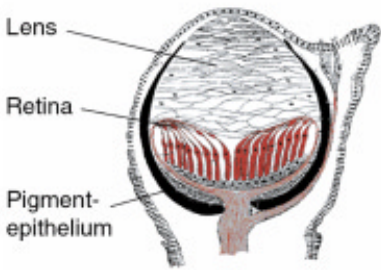

Cardium eye

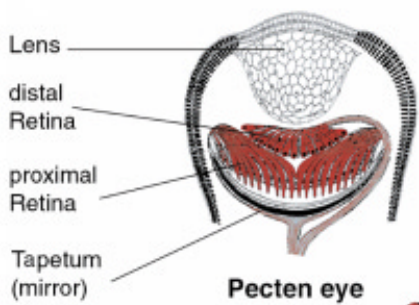

have fewer Pax genes than Bilaterians, and so far no bona fide Pax 6 homolog has been found in corals (Miller et al., 2000; Plaza et al., 2003), in hydrozoans (Gröger et al., 2000; Sun et al., 2001) and in cubozoans (Sun et al., 1997; Kozmik et al., 2003). Until the complete genomic sequences are available, the possibility that a bona fide $\operatorname{Pax} 6$ gene exists in cnidarians cannot be excluded. However, the recent data on the Pax B gene of Tripedalia (Kozmik et al., 2003) a cubomedusan jellyfish with highly developed eyes, suggest that cnidarians have an ancestral precursor gene to Pax
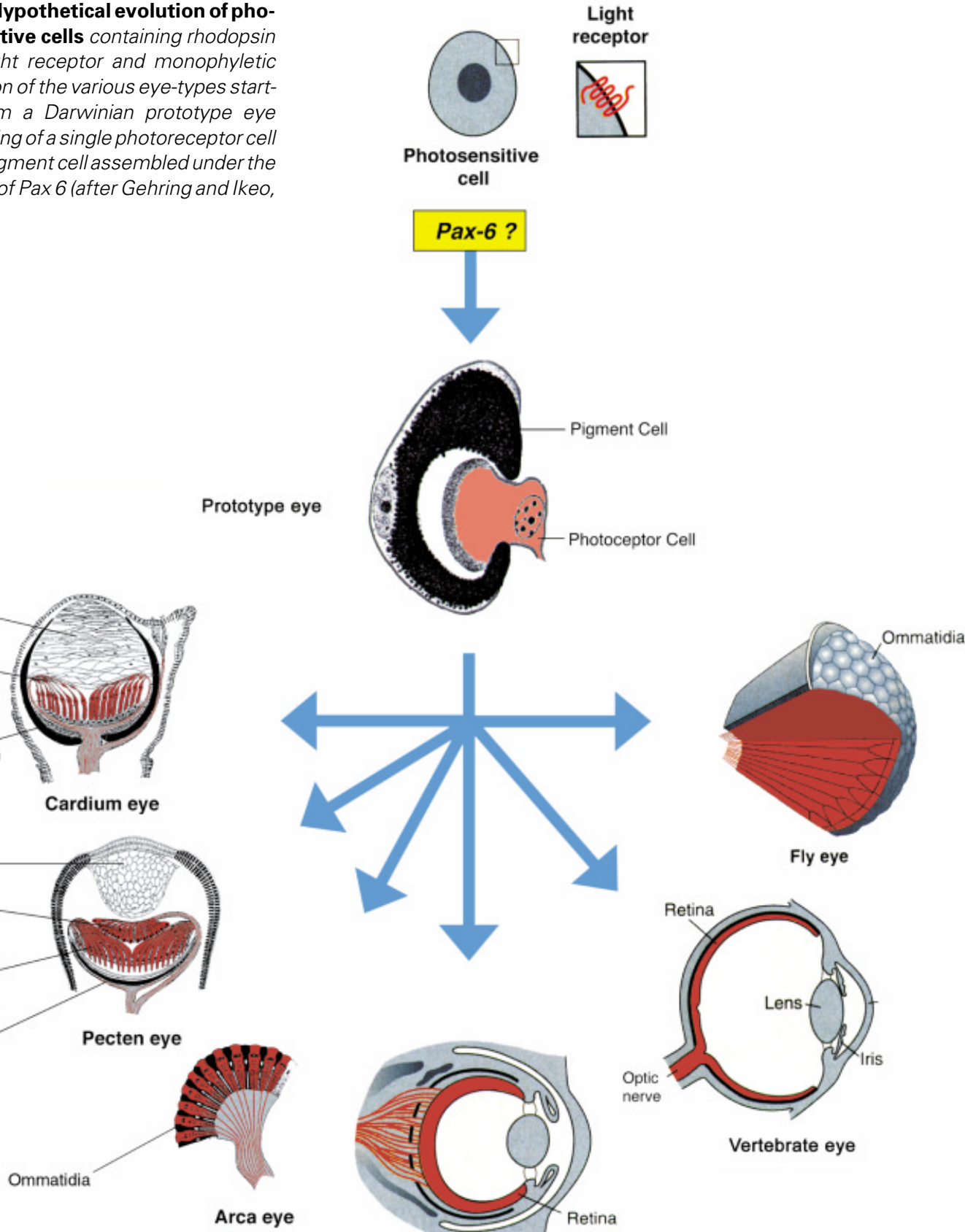

Fly eye
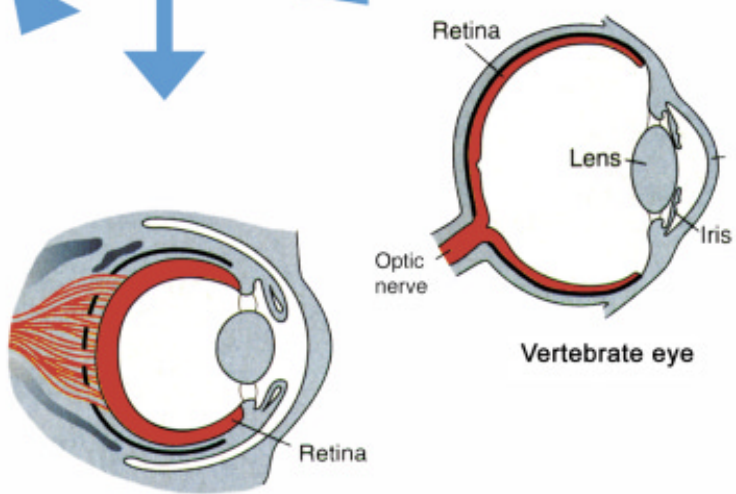

Cephalopod eye

Molluscs 

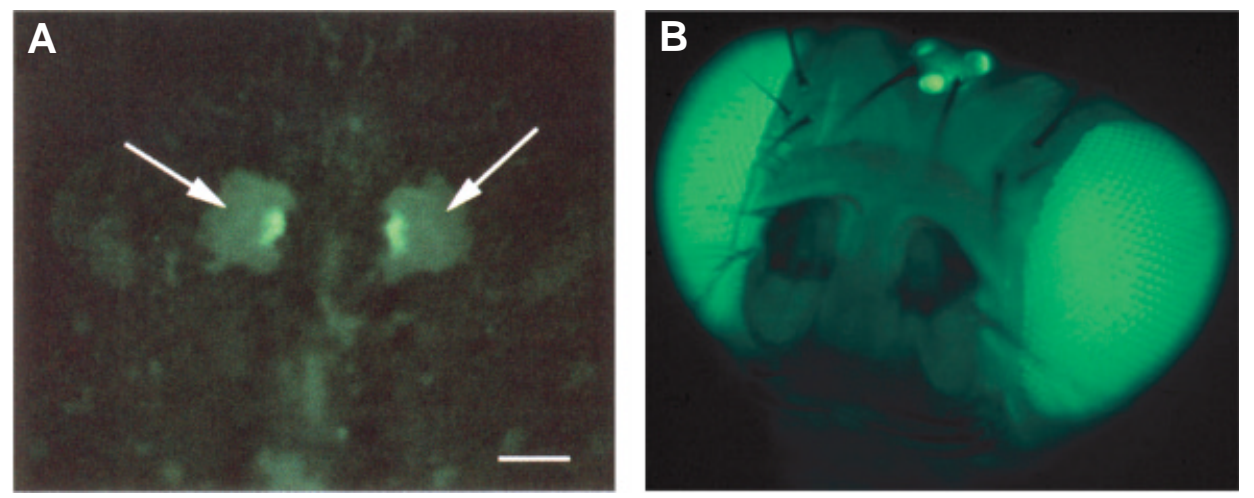

Fig. 6. (A) Green-eyed planarian (Girardia tigrina) transformed by electroporation with a Hermesderived vector driving Green Fluorescent Protein (GFP) with a Pax 6 specific P3 enhancer (after González-Estévez etal., 2003). (B) Greeneyed Drosophila carrying a GFP gene driven by the P3 enhancer (Courtesy of Dr. Teruyuki Niimi).

6 which unites sequences and functions of both Pax 6 and Pax 2 into a single gene. On the one hand, Pax B of Tripedalia has a paired box which more closely ressembles the one of mammalian Pax 2 (82\% identity) than that of Pax 6 (75\% identity). Furthermore, the three aminoacids at positions critical for DNA binding (Czerney and Busslinger, 1995) are identical to those found in Pax 2 / 5 / 8. Pax B also contains a Pax 2 - like octapeptide which is absent in $\mathrm{Pax} 6$. On the other hand, the homeodomain of $\mathrm{Pax}$ $\mathrm{B}$ is much more closely related to mammalian $\mathrm{Pax} 3 / 7$ and $\mathrm{Pax}$ 6 (with $60 \%$ and $55 \%$ sequence identity respectively), whereas Pax 2 has a partial homeobox encoding only the first_-helix of the homeodomain. The mosaic nature of $\mathrm{Pax} B$ is also supported by functional studies; the ectopic overexpression of $\mathrm{Pax} B$ under the appropriate enhancer can rescue the $\mathrm{Pax} 2^{-/-}$(spa pol) phenotype and generate ectopic eyes in Drosophila, indicating that Tripedalia Pax B unites the functions of both Pax 2 and Pax 6. Since the phylogenetic analysis of the paired domains (Sun et al., 2001) indicates that $P a x 2$ / 5 / 8 are most closely related to $P a x 6$ / 4, we interpret these data as a strong indication that $P a x B$ is the precursor gene of $\mathrm{Pax} 6$ and Pax 2 which controls eye morphogenesis in cnidarians and subsequently became duplicated in Bilateria to give rise to $\operatorname{Pax} 6$ and $\operatorname{Pax} 2$. This interpretation is entirely consistent with the available data, and does not contradict the hypothesis of a monophyletic origin of the eye. Kozmik et al., also consider the possibility Pax-B is derived from an ancestral Pax gene which duplicated and diverged into Pax 2 and Pax 6 in bilateria. However, they conclude that $\operatorname{Pax} 6$ is not a universal regulator of eye development and raise the possibility for an independent evolutionary origin of eyes sophisticated in Cnidarians. The importance of gene duplication and divergence in evolution will be discussed in more detail below.

The detailed morphological analysis of the planula larva of Tripedalia has revealed another primitive feature of this jellyfish (Nordström et al., 2003). This larva has an extremely simple organization without any apparent nervous system, but $10-15$ pigment-cup ocelli. These ocelli are single cell structures, containing shielding pigment granules and putative photosensory microvilli (Fig. 7A). These rhabdomeric photoreceptor cells have no detectable neural connections to any other cells, but each contains a well-developed motor-cilium, appearing to be the only means by which light can control the behavior of the planula larva. Thus, these photoreceptor cells are uniting the structures and functions of photoreception, pigmentation, and ciliary movement into a single cell, similar to the situation in unicellular protists. We propose that in the course evolution this cell has duplicated and differentiated into at least two different cell types, a photoreceptor cell and a pigment cell as they are found in adult Tripedaliajellyfish and in the prototypic eyes of planarians.

\section{The origin of eyes and brain}

Gregory (1967) has considered the question of whether the eyes or the brain came first in evolution, assuming that the evolution of the mechanism of visual perception must entail the separate elaboration of eyes and brain. He regards the information given by the eyes as of indirect use to living creatures, since considerable "computing" is required to make any use of visual information. Gregory therefore considers it reasonable to suppose that vision is a lately acquired sense. However, the fact that singlecelled protists can determine the direction of the incoming light, having presumably limited computing ability, argues against this hypothesis.

Archaeal (type I) rhodopsins differ from animal visual opsins in that they contain all-trans retinal which upon light absorption undergoes a 13-cis isomerization. Bacteriorhodopsin functions as a light-driven proton pump. The function of bacterial sensory rhodopsins is very similar. A proton within the retinal binding site is displaced after retinal isomerization, however, the proton is not released, but instead it drives conformational changes within the rhodopsin and the attached transducer protein (Htr) (Spudich etal., 2000). Microbial opsins have also been found in protists like Chlamydomonas and both phototactic and photophobic responses are mediated by rhodopsins with a microbial type all-trans chromophore. More recently two additonal rhodopsins have been identified in Chlamydomonas which serve as a lightgated proton channel, and a directly light-gated cation-selective membrane channel respectively (Nagel et al., 2002 and 2003). Animal (type II) rhodopsins contain 11-cis retinal which after light excitation isomerizes into all-trans and its evolutionary precursors remain to be identified. Rüdiger Wehner (per. comm.) has proposed the idea that rhodopsin may be considered as a chemoreceptor with a covalently bound ligand, retinal. In this case the ligand does not have to be bound by the receptor in order to activate it as in chemoreception, but it can be activated by photons. There is in fact some evidence supporting the hypothesis that rhodopsin is derived from chemoreceptors, since Klein et al., (1988) have found significant sequence homology between rhodopsin and the cyclic AMP receptor of Dictyostelium, which serves as a chemoattractant receptor. This lends support to the idea that the olfactory and visual systems are closely related and that the visual system may have 
A
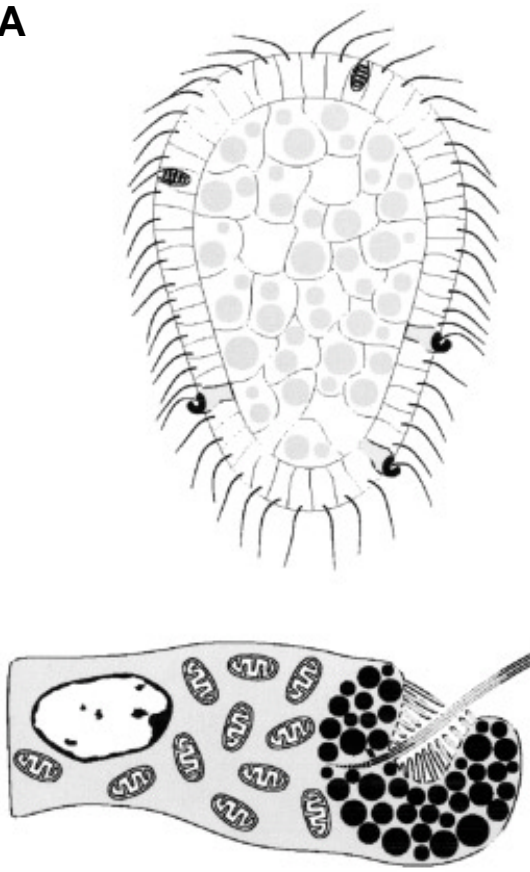

B

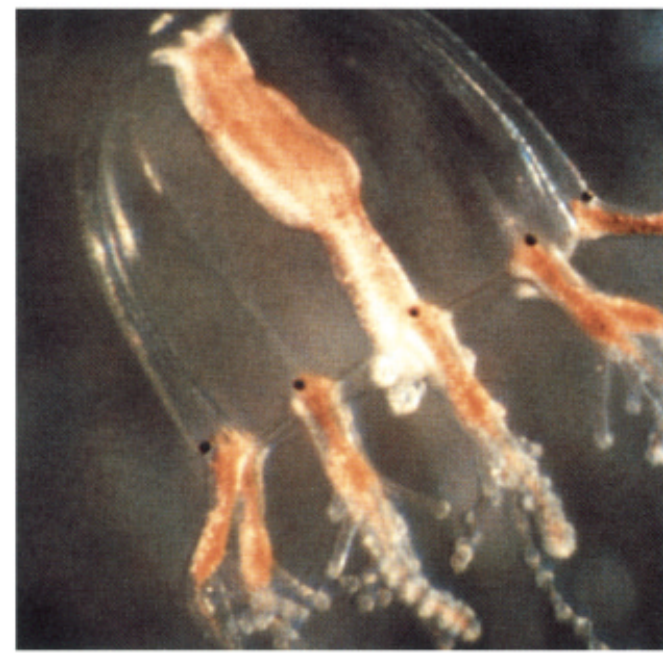

Fig. 7. Ocelli and eyes of jellyfish. (A) Planula larva of Tripedalia with single-celled ocelli (from Nordström et al., 2003). (B) Cladonema, the eyes are located at the base of the tentacles (Courtesy of Volker Schmid).

fact that eye, nose and brain are under the control of the same gene argues that these organs have co-evolved.

Concerning the question of who came first the eyes, the nose or the brain we have proposed that the sensory organs proceeded the evolution of the brain (Gehring and lkeo, 1999). The sensory organs are gathering information, whereas the brain is an information processing organ, similar to a computer. If no information is acquired, there is no need for an elaborate information processing organ. As more and more information is acquired by the sensory organs, the brain evolves in parallel to process this information and transmit it to the effector organs like the muscles. Evidence for this hy-

evolved from chemoreception. In this context it is important to point out that Pax 6 is not only involved in eye morphogenesis but also in the development of the nose and other chemosensory organs, and in brain morphogenesis as well. In both mammals and insects Pax 6 is a selector gene which specifies not only the eye as such, but the eye in its proper context of other head structures and the brain. Deletion of Pax 6 in mice removes not only the eyes, but also the pineal organ, a large part of the forebrain and the nose (nasal epithelium and nasal openings). In Drosophila eyeless deletions remove the compound eyes, whereas toy null mutations remove the head capsule with the ocelli, the antennae and the maxillary palps, but leave the distal part of the proboscis intact. In the brain the mushroom bodies and the optic lobes where the photoreceptor axons project to, are also affected. In contrast to other homeotic mutations which lead to homeotic transformations, null mutations in Pax 6 lead to apoptosis and loss of the respective organs. The pothesis comes from the analysis of jellyfish like Cladonema, which have highly evolved eyes, but no brain (Fig. 7B). The eyes are located at the base of the tentacels and transmit their information directly to the muscles without processing by a brain. There are very few interneurons between the eyes and the muscles, and there is only a ring nerve around the bell margin, which may coordinate the movements of the tentacles, but there is no real brain, which would integrate the various sensory inputs and give a coordinated response. Of course, one may argue that jellyfish originally had a brain, but have reduced it in the course of evolution. However, there is no selective advantage to loose the brain in a free-living pelagic animal. On the contrary, there is selective pressure to maintain it. Animals living underground or in caves may loose their eyes because of lack of selective pressure, however, they retain their brain. Parasites may even reduce their brains, by adapting to their hosts and become extremely reduced to repro-
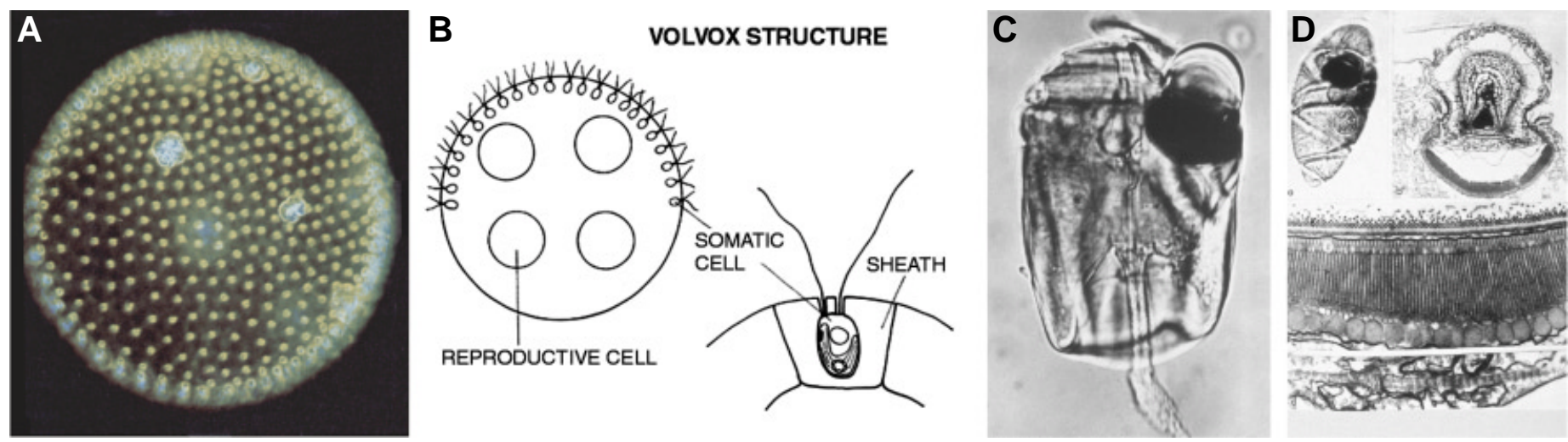

Fig. 8. Eye organelles (A, B) Volvox structure. Somatic cells with an ocellus in their chloroplast. (C) Erythropsis (Dinoflagellate) with cornea-, lens-and pigment cup-like structures. (D) Warnowia (Dinoflagellate). Electronmicrograph showing stacked membranes resembling the rhabdomeres in the retina of multicellular organisms (after Greuet, 1965). 
duction "machines", but free-living organisms can neither dispense with their sensory organs nor their brains. Therefore, I consider it likely that the eyes came before the brain. This point of view is supported by the evolution of eye organelles in planula larvae of Tripedalia which have single-celled photoreceptor organelles apparently in the absence of any nervous system (see above). The same applies to protists like Chlamydomonas, which has an eye organelle with a rhodopsin-related photosensitive pigment and a pigmented eyespot, which functions as a directional antenna and allows it to determine the direction of the incoming light. Analogous to jellyfish larvae the eye organelle in Chlamydomonas is located close to the effector organelle, the flagellum, and the information is transmitted directly from the eye organelle to the flagellum without an intervening information processing organelle.

\section{Evolution by duplication and divergence}

The evolution by duplication (or replication) and subsequent divergence appears to be a general principle that applies to all levels of biological organization. It applies to DNA molecules, which replicate and diverge by mutation; to genes like eyelessand twin of eyelessor Pax 6and Pax 2as examples which first duplicate and then diverge in evolution; to cells like sensory-motoneurons in C. elegans which in the course of evolution differentiate into sensory and motoneurons, or pigmented photoreceptor cells in the planula larvae, which later differentiate into separate photoreceptor and pigment cells. It is conceivable that photoreceptor and pigment cells might also evolved independently by differentiation from other cell types. However, the fact that the optic cup in vertebrates gives rise to both retinal photoreceptor cells and retinal pigment cells supports a common evolutionary origin. The other melanocytes arise from the neural crest and apparently have a different evolutionary origin. The same applies to the eye disc of Drosophila which also gives rise to both photoreceptor and pigment cells, which in this case contain ommochromes and drosopterins rather than melanin. The principle of duplication and divergence even applies to multicellular entities like body segments, and finally to complete organisms like the different sexes in sexually dimorphic organisms, or casts in social insects and even to different populations of organisms. The selective advantage of duplication or replication prior to divergence, over direct conversion, lies in fact that the previous function is retained by one of the duplicated entities, which meets the selective pressure, whereas the duplicate is free to diverge.

\section{The evolution of photoreception}

The origin of photoreceptor cells indicated in Fig. 5 (at the top) is largely a matter of speculation. Eventhough bacteria have sensory rhodopsins there is no detectable sequence homology between bacteriorhodopsins and metazoan visual rhodopsins (Spudich et al., 2000). However, the two may still be phylogenetically related, since their three-dimensional structures with seven membrane-embedded _helices are very similar, and they all share the same chromophore, retinal, which is attached in a Schiff base linkage to a lysine residue in the seventh _-helix. The most primitive organism in which a rhodopsin has been found which may be related to animal opsins is Volvox, a colonial green alga in the transition zone between protists and multicellular organism. The primary amino acid sequence of Volvoxrhodopsin matches 10 out of 27 residues in a consensus sequence of the retinal binding site with a group of invertebrate rhodopsins (Ebnet et al., 1999). Volvox is a sphere formed by individual flagellates each equipped with an "eye spot" located in the thylacoid membranes of their chloroplast (Fig. 8 A,B). This raises the possibility that photoreception initially evolved in cyanobacteria which later were taken up as symbionts into eukaryotic cells and gave rise to chloroplasts. During the transition from unicellular to multicellular organisms, each cell of the primitive multicellular organism, like Volvox, may have been equipped with a photoreceptor organelle, and the eyes may have evolved from such an ancestral state by cell differentiation and organogenesis.

However, there is an alternative hypothesis which is raised by the finding that some single-celled dinoflagellates, like Erythropsis and Warnovia have extremely highly developed photoreceptor organelles with cornea-, lense-, pigment cup - and retina-like structures consisting of stacked membranes closely ressembling rhabdomeres (Greuet, 1965), all in a single cell (Fig. 8 C,D). Since Erythropsis and Warnovia, in contrast to the vast majority of dinoflagellates, lack chloroplasts, Greuet has suggested that the eye organelles might be derived from chloroplasts. In this respect it is interesting to note that in another dinoflagellate (Pyrocystis lunula) a proteorhodopsin gene has been identified which seems to be involved in circadian photoreception (Okamoto and Hastings, 2003). The expression of this gene is cyclic during the normal circadian light cycle and is overexpressed during phase shifting like that of other circadian genes. Since this gene is similar to bacterial proteorhodopsin genes required for phototrophy (Beja et al., 2001), these findings support the idea of a cyanobacterial origin of photoreception. Since dinoflagellates are frequently found as symbionts in cnidarians, I would like to suggest the hypothesis that some of the genes involved in photoreception may have been acquired by cnidarians from dinoflagellate symbionts. This leads to a kind of "Russian doll" model which assumes that photoreception originated in cyanobacteria, which were taken up by a primary eukaryotic host giving rise to primary chloroplasts surrounded by a cyanobacterial double membrane. The primary host in turn was taken up by dinoflagellates giving rise to secondary chloroplasts surrounded by triple membranes. In some dinoflagellate species these secondary chloroplasts might have evolved into eye organelles. In a further step of symbiosis, these dinoflagellates may have been taken up by cnidarians and the genes involved in photoreception transferred to the nucleus of the cnidarian host. We are currently pursuing both of these alternative hypotheses to shed some light on the origin and evolution of photoreception.

\section{References}

ARENDT, D. and WITTBRODT, J. (2001). Reconstructing the eyes of Urbilateria. Phil. Trans. Roy. Soc. London B356: 1545-1563.

ARENDT, D., TESSMAR, K., DE CAMPOS-BAPTISTA, M.I., DORRESTEIJN, A. and WITTBRODT, J. (2002). Development of pigment-cup eyes in the polychaete Platynereis dumerilii and evolutionary conservation of the larval eyes in Bilateria. Development 129: 1143-1154.

ARENDT, D. (2003). Evolution of eyes and photoreceptor cell types. Int. J. Dev. Biol. 47: 563-571.

BEADLE, G.W. and EPHRUSSI, B. (1936). The differentiation of eye pigments in Drosophila as studied by transplantation. Genetics 21: 225-247. 
BEJA, O., SPUDICH, E.N., SPUDICH, J.L., LECLERC, M. and DELONG, E.F. (2001). Proteorhodopsin phototrophy in the ocean. Nature 411: 786-789.

BERGHAMMER, A.J., KLINGLER, M. and WIMMER, E.A. (1999). Genetic techniques: A universal marker for transgenic insects. Nature 402: 370-371.

BRAND, A. H. and PERRIMON, N. (1993). Targeted gene expression as a means of altering cell fates and generating dominant phenotypes. Development 118: 401-415.

CZERNY, T. and BUSSLINGER, M. (1995). DNA-binding and transctivation properties of $\operatorname{Pax} 6$ : Three amino acids in the paired domain are responsible for the different sequence recognition of Pax-6 and BSAP (Pax-5). Mol. Cell. Biol. 15: 2858-2871.

CZERNY, T., HALDER, G., CALLAERTS, P., KLOTER, U., SOUABNI, A., GEHRING, W.J. and BUSSLINGER, M. (1999). Twin of eyeless, a second Pax-6 gene of Drosophila, acts upstream of eyeless in the control of eye development. Mol. Cel/3: 297-307.

DARWIN, CHARLES (1882). The Origin of Species by means of Natural Selection ( $6^{\text {th }}$ edition, John Murray, London).

DAVIS, R.J., TAVSANLI, B.C., DITTRICH, C., WALLDORF, U. and MARDON, G. (2003). Drosophila retinal homeobox (drx) is not required for establishment of the visual system, but is required for brain and clypeus development. Dev. Biol. 259: $272-287$.

EBNET, E., FISCHER, M., DEININGER, W. and HEGEMANN, P. (1999). Volvoxrhodopsin, a light-regulated sensory photoreceptor of the spheroidal green alga Volvox carteri. Plant Cel/11: 1473-1484.

EGGERT, T., HAUCK, B., HILDEBRANDT, N., GEHRING, W.J. and WALLDORF, U. (1998). Isolation of a Drosophila homolog of the vertebrate homeobox gene $\mathrm{Rx}$ and its possible role in brain and eye development. Proc. Natl. Acad. Sci. USA 95: 2343-2348.

GEHRING, W.J. and IKEO, K. (1999). Pax 6 mastering eye morphogenesis and eye evolution. Trends Genet. 15: 371-377.

GERHART, J. and KIRSCHNER, M. (1997). Cells, Embryos and Evolution. Blackwe/l Science, Oxford. p. 112.

GOLDSMITH, T.H. (1990). Optimization, constraint, and history in the evolution of eyes. Q. Rev. Biol. 65: 281-322.

GONZALEZ-ESTEVEZ, C., MOMOSE, T., GEHRING, W.J. and SALO, E. (2003). Planarian transgenic lines obtained by electroporation using transposon-derived vectors and an eye-specific GFP marker. Proc. Natl. Acad. Sci. USA 100: 14046-14051.

GREGORY, R.L. (1967). Origin of eyes and brains. Nature 28: 369-372.

GREUET, C. (1965). Structure fine de l'ocelle d'Erythropsis pavillardi Hertwig, pteridinien Warnowiidae Lindemann. C.R. Acad. Sci. (Paris). 261: 1904-1907.

GROGER, H., CALLAERTS, P., GEHRING, W.J. and SCHMID, V. (2000). Characterization and expression analysis of an ancestor-type Pax gene in the hydrozoan jellyfish Podocoryne carnea. Mech. Dev. 94: 157-169.

HADORN, E. (1961). Developmental Genetics and Lethal Factors. Wiley, New York.

HALDER, G., CALLAERTS, P. and GEHRING, W.J. (1995). Induction of ectopic eyes by targeted expression of the eyeless gene in Drosophila. Science 267: 1788-1792.

HILL, R.E. et al., (1991). Mouse Small eye results from mutations in a paired-like homeobox-containing gene. Nature 354: 522-525.

HAMBURGER, V. (1988). The Heritage of ExperimentalEmbryology:Hans Spemann and the Organizer. New York, Oxford: Oxford University Press.

HESSE, R. (1897). Untersuchungen über die Organe der Lichtempfindungen bei niederen Thieren. II. Die Augen der Plathelminthen. Z. wiss. Zool. Band 62: 527582.

HOCHMAN, B., GLOOR, H. and GREEN, M.M. (1964). Analysis of Chromosome 4 in Drosophila Melanogaster, I. Spontaneous and X-Ray Induced Lethals. Genetica 35: 109-126.

HOGE, M.A. (1915). Another gene in the fourth chromosome of Drosophila. Amer. Naturalist 49: 47-49.

HORN, C. and WIMMER, E.A. (2000). A versatile vector set for animal transgenesis. Dev. Genes Evol. 210: 630-637.

KAMMERMEIER, L., LEEMANS, R., HIRTH, F., FLISTER, S., WENGER, U., WALLDORF, U., GEHRING, W.J. and REICHERT, H. (2001). Differential expression and function of the Drosophila Pax 6 genes eyeless and twin of eyeless in embryonic central nervous system development. Mech. Dev. 103: 71-78.

KLEIN, P.S., SUN, T.J., SAXE III, C.L., KIMMEL, A.R., JOHNSON, R.J. and DEVREOTES, P.N. (1988). A chemoattractant receptor control development in Dictyostelium discoideum. Science 241: 1407-1472.

KOZMIK, Z., DAUBE, M., FREI, E., NORMAN, B., KOS, L., DISHAW, L.J., NOLL, M. and PIATIGORSKY, J. (2003). Role of Pax Genes in Eye Evolution: A Cnidarian Pax BGene Uniting Pax 2 and Pax 6 Functions. Developmental Cell 5: 773-785.

KRONHAMN, J., FREI, E., DAUBE, M., JIAO, R., SHI, Y., NOLL, M. and RASMUSONLESTANDER, A. (2002). Headless flies produced by mutations in the paralogous Pax 6 genes eyeless and twin of eyeless. Development 129: 1015-1026.

KURUSU, M., NAGAO, T., WALLDORF, U., FLISTER, S., GEHRING, W.J. and FURUKUBO-TOKUNAGA, K. (2000). Genetic control of development of the mushroom bodies, the associative learning centers in the Drosophilabrain, by the eyeless, twin of eyeless, and dachshundgenes. Proc. Natl. Acad. Sci. USA 97: 2140-2144.

LAND, M.F. and NILSSON, D.-E. (2002). Animal Eyes. Oxford University Press, Oxford. p. 12

LEWIS, W.H. (1904). Experimental studies on the development of the eye in amphibia. I. On the origin of the lens in Rana palustris. Amer. J. Anat. 3: 505536

LEWIS, W.H. (1907). Experimental studies on the development of the eye in amphibia. III. On the origin and differentiation of the lens. Amer. J. Anat. 6: 473509.

MATHERS, P.H., GREENBERG, A., MAHON, K.A. and JAMRICH, M. (1997). The $\mathrm{Rx}$ homeobox gene is essential for vertebrate eye development. Nature 387 : 603-607.

MAYR, E. (2001). What Evolution Is. Basic Books, New York.

MICHAUT, L., FLISTER, S., NEEB, M., WHITE, K., CERTA, U. and GEHRING, W.J. (2003). Analysis of the eye developmental pathway in Drosophila using DNA microarrays. Proc. Natl. Acad. Sci. USA 100: 4024-4029.

MILLER, D.J., HAYWARD, D.C., REECE-HOYES, J.S., SCHOLTEN, I., CATMULL, J., GEHRING, W.J., CALLAERTS, P., LARSEN, J.E. and BALL, E.E. (2000). Pax gene diversity in the basal cnidarian Acropora millepora (Cnidaria, Anthozoa): Implications for the evolution of the Pax gene family. Proc. Natl. Acad. Sci. USA 97: 4475-4480.

MORGAN, T.H. (1934). Embryology and Genetics, Columbia University Press, New York.

NAGEL, G., OLLIG, D., FUHRMANN, M., KATERIYA, S., MUSTI, A.M., BAMBERG, E. and HEGEMANN, P. (2002). Channelrhodopsin-1: A light-gated proton channel in Green Algae. Science 296: 2395-2398.

NAGEL, G., SZELLAS, T., HUHN, W., KATERIYA, S., ADEISHVILI, N., BERTOLD, P., OLLIG, D., HEGEMANN, P. and BAMBERG, E. (2003). Channelrhodopsin2, a directly light-gated cation-selective membrane channel. Proc. Nat. Acad. Sci. USA 100: 13940-13945.

NILSON, D.-E.(1994). Eyes as optical alarm system in fan worms and ark clams. Phil. Trans. R. Soc. London B346: 195-212.

NORDSTROM, K., WALLEN, R., SEYMOUR, J. and NILSSON, D. (2003). A simple visual system without neurons in jellyfish larvae. Proc. R. Soc. Lond. B 270: 2349-2354.

OKAMOTO, O.K. and HASTINGS, J.W. (2003). Novel dinoflagellate clock-related genes identified through microarray analysis. J. Phycol. 39: 519-526

ONUMA, Y., TAKAHASHI, S., ASASHIMA, M., KURATA, S. and GEHRING, W.J. (2002). Conservation of Pax-6 function and upstream activation by Notch signaling in eye development of frogs and flies. Proc. Natl. Acad. Sci. USA99: 2020-2025.

PINEDA, D., GONZALEZ, J., CALLAERTS, P., IKEO, K., GEHRING, W.J. and SALO, E. (2002). Searching for the prototypic eye genetic network: Sine oculis is essential for eye regeneration in planarians. Proc. Natl. Acad. Sci. USA 97: 4525-4529.

PLAZA, S., DE JONG, D., GEHRING, W.J. and MILLER, D.J. (2003). DNA-Binding Characteristics of Cnidarian Pax-C and Pax-B Proteins In Vivo and In Vitro: No Simple Relationship With the Pax-6 and Pax-2/5/8 Classes. J. Experimental Zoology (Mol. Dev. Evol.) 299B: 26-35 
PUNZO, C., SEIMIYA, M., FLISTER, S., GEHRING, W.J. and PLAZA, S. (2002). Differential interactions of eyeless and twin of eyeless with the sine oculis enhancer. Development 129: 625-634.

SALVINI-PLAWEN, L and MAYR, E. (1977) in Evolutionary Biology, (Vol. 10) (Hecht, M.K., Steere, W.C. and Wallace, B., eds), pp. 207-263, Plenum Press.

SPEMANN, H. (1901). Über Correlationen in der Entwicklung des Auges. Verhandl. Anat. Ges. 15, 61-79.

SPEMANN, H. (1936). Experimentelle Beiträge zu einer Theorie der Entwicklung (Verlag Julius Springer, Berlin).

SPUDICH, J.L., YANG, C.S., JUNG, K.H. and SPUDICH E.N. (2000). Retinylidene Proteins: Structures and Functions from Archaea to Humans. Annu. Rev. Cell Dev. Biol. 16: 365-392.
SUN, H., RODIN, A., ZHOU, Y., DICKINSON, D.P., HARPER, D.E., HEWETTEMMETT, D. and LI, W.H. (1997). Evolution of paired domains: isolation and sequencing of jellyfish and hydra Pax genes related to Pax-5 and Pax-6. Proc. Natl. Acad. Sci. USA 94: 5156-5161.

SUN, H., DICKINSON, D.P., COSTELLO, J., LI, W.H. (2001). Isolation of Cladonema Pax- $B$ Genes and Studies of the DNA-Binding Properties of Cnidarian Pax Paired Domains. Mol. Biol. Evol. 18: 1905-1918.

TON, C.C. et al., (1991). Positional cloning and characterization of a paired box-and homeobox-containing gene from the aniridia region. Cel/67: 1059-1074.

WALTHER, C. and GRUSS, P. (1991). Pax 6, a murine paired box gene, is expressed in the developing CNS. Development 113: 1435-1449. 